\title{
MET overexpression and gene amplification in NSCLC: a clinical perspective
}

\author{
This article was published in the following Dove Press journal: \\ Lung Cancer:Targets and Therapy \\ 18 June 2013 \\ Number of times this article has been viewed
}

\section{Lorenza Landi \\ Gabriele Minuti \\ Armida D'Incecco \\ Jessica Salvini \\ Federico Cappuzzo}

Medical Oncology Department, Istituto Toscano Tumori, Ospedale Civile, Livorno, Italy
Correspondence: Federico Cappuzzo Istituto Toscano Tumori,

Ospedale Civile, viale Alfieri 36, Livorno 57100, Italy

Tel +39058622 3189

$\mathrm{Fax}+390586223457$

Email f.cappuzzo@gmail.com

\begin{abstract}
The transmembrane tyrosine kinase mesenchymal-epidermal transition (MET) receptor and its ligand, hepatocyte growth factor, also known as scatter factor, have recently been identified as novel promising targets in several human malignancies, including non-small cell lung cancer (NSCLC). Amplification, mutation, or overexpression of the MET gene can result in aberrant activation of the MET axis, leading to migration, invasion, proliferation, metastasis, and neoangiogenesis of cancer cells, suggesting that interfering with the MET/hepatocyte growth factor pathway could represent a potential antitumor strategy. While the role of MET mutations in NSCLC is not as yet fully understood, retrospective studies have shown that an increased MET gene copy number is a negative prognostic factor. In NSCLC, amplification of the MET gene is a relatively rare event, occurring in approximately $4 \%$ of patients not previously exposed to systemic therapies and in up to $20 \%$ of patients with acquired resistance to epidermal growth factor receptor tyrosine kinase inhibitors. In preclinical models, the presence of MET amplification is a predictor of high sensitivity to anti-MET compounds, and several agents have entered in clinical trials for patients having advanced disease, with promising results. The aim of the present review is to summarize available data on the role of MET in NSCLC and to describe therapeutic strategies under investigation.
\end{abstract}

Keywords: mesenchymal-epidermal transition, hepatocyte growth factor, epidermal growth factor receptor, non-small cell lung cancer

\section{Introduction}

For many years, non-small cell lung cancer (NSCLC) has been considered as a unique monochromatic disease with an unfavorable prognosis and limited therapeutic options. ${ }^{1}$ This old perspective is now changing dramatically with identification of the molecular events driving tumor growth and development, leading to so-called targeted therapies. ${ }^{2}$ Up until now, gene mutations, gene amplification, and gene rearrangements have been among the most widely investigated aberrations in human cancer.

In NSCLC, identification of epidermal growth factor receptor gene (EGFR) mutations and EML4 -anaplastic lymphoma kinase ( $A L K)$ translocation led to definition of different clinical entities with different therapeutic opportunities. ${ }^{3-7}$ Clinical trials confirmed that targeted therapies are the best treatment option we can offer today to our patients and only when the target is present, with no benefit or even a detrimental effect when a targeted agent is given in unselected populations. ${ }^{8-19}$ Seven large randomized Phase III trials conducted in more than 1400 patients harboring classical EGFR mutations, such as a deletion in exon 19 or an L858R substitution in exon 21, have demonstrated the superiority of gefitinib, erlotinib, and afatinib in terms of response 
rate and progression-free survival when compared with conventional platinum-based chemotherapy. ${ }^{8-14}$ Although no formal overall survival advantage has emerged from the aforementioned trials, mainly because of a drug crossover effect, median survival reached 2-3 years, indicating that EGFR tyrosine kinase inhibitors are changing the natural history of EGFR-mutated NSCLC. ${ }^{8-15}$ More recently, two studies, A8081001 and PROFILE 1007, established crizotinib as the best treatment for the small population of patients with ALK-translocated NSCLC. ${ }^{17,18}$

Unfortunately, often medicine is like Janus, the God with two faces, and the dark side in this context is represented by emergence of acquired resistance. Indeed, despite dramatic initial tumor regression, virtually all patients exposed to such targeted agents develop resistance after a median time of 10 months and inevitably progress and die from their disease.

Amplification of the MET gene has been recognized as one of the most prominent mechanisms responsible for secondary resistance to EGFR tyrosine kinase inhibitors, and several sets of preclinical and clinical data indicate that coinhibition of MET and EGFR is a potentially effective strategy to overcome acquired resistance to these agents. ${ }^{20,21}$ Further, because of its central role in the proliferation and metastasis of cancer, MET has recently emerged as a potential tumor driver and is also a promising target in NSCLC ${ }^{22}$ Here, we discuss the role of the mesenchymal-epidermal transition (MET) receptor, its abnormalities in cancer, and the clinical impact of anti-MET strategies in NSCLC.

\section{MET and NSCLC}

The $M E T$ gene encodes for the hepatocyte growth factor (HGF, also known as scatter factor) receptor, a transmembrane tyrosine kinase heterodimer protein involved in a complex signaling apparatus. ${ }^{23} \mathrm{HGF}$ is produced particularly by stromal tissues and is also expressed in a broad spectrum of mesenchymal cells. Binding of HGF to the extracellular domain of the receptor determines autophosphorylation of the catalytic site and consequently activation of the downstream cascade in a domino-effect fashion (Figure 1). ${ }^{24,25}$

In physiological conditions, such as during embryogenesis or organogenesis, ${ }^{26-28}$ activation of the MET/HGF pathway regulates a wide network of signaling that leads to "invasive growth", a phenomenon in which the cell gains the ability to move from its original niche toward the surrounding microenvironment, growing and improving proliferation and survival. ${ }^{29}$ This process becomes quiescent in adulthood, but different stressing conditions, such as angiogenesis or hypoxia,

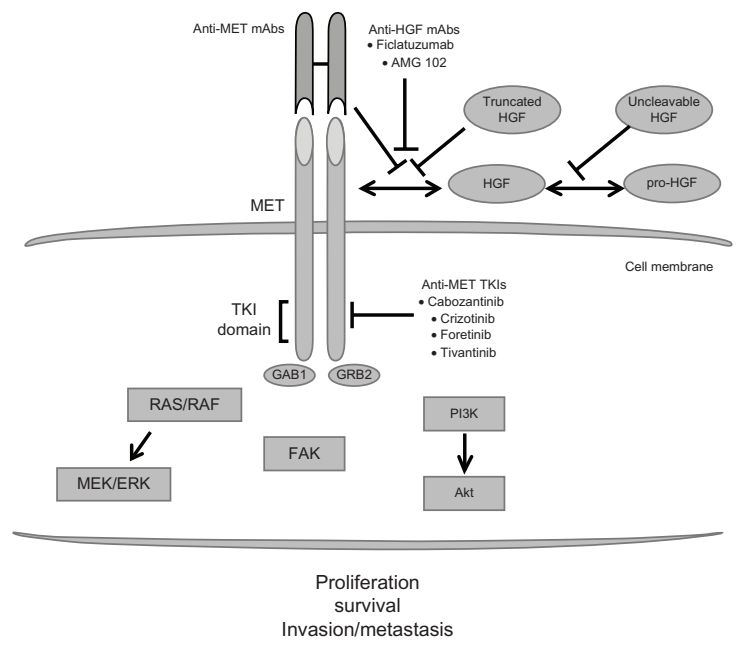

Figure I Hepatic growth factor/mesenchymal-epidermal transition axis. Abbreviations: HGF, hepatic growth factor; mAbs, monoclonal antibodies; TKI, tyrosine kinase inhibitor; PI3K, Phosphatidylinositide 3-kinase; MET, mesenchymalepidermal transition.

can lead to its reactivation. Notably, the HGF/MET axis also plays an important role in regulating tissue homeostasis and the inflammatory tissue response, as elucidated in preclinical models of degenerative diseases, including nephropathies and multiple sclerosis..$^{30-32}$

In cancer, aberrant activation of the MET/HGF pathway, either through ligand-dependent or ligand-independent mechanisms, is a frequent event and has been described in several human malignancies, including NSCLC, ${ }^{33}$ glioma, ${ }^{34}$ and gastroesophageal, $, 35,36$ ovarian, ${ }^{37}$ breast, ${ }^{38}$ kidney, ${ }^{39}$ and liver cancer, ${ }^{40}$ strongly supporting the hypothesis that interfering with the MET/HGF pathway could represent a potential antitumor strategy.

Several mechanisms are responsible for MET dysregulation, including protein overexpression, gene amplification, or gene mutation. Overexpression of MET is frequently observed in human cancer, including NSCLC, where this event is observed in $25 \%-75 \%$ of cases. ${ }^{41-43}$ In the absence of gene amplification, overexpression of MET could be related to transcriptional upregulation, and in some tumors the extent of expression has correlated with disease extension and outcome. ${ }^{44-46}$ The presence of a high number of receptors on the cell surface causes receptor oligomerization, thus determining an increased sensibility to suboptimal ligand concentrations.

MET gene amplification has been reported in different human cancers, including NSCLC, where this event is reported in approximately $4 \%$ of cases. ${ }^{47}$ Several studies have shown that an increased $M E T$ gene copy number is an independent negative prognostic factor in surgically resected NSCLC. ${ }^{47,48}$ In the study conducted by Okuda et al, a total 
of 534 surgically resected NSCLCs were analyzed for $M E T$ gene copy number by quantitative real-time polymerase chain reaction. The study showed that an increased MET gene copy number was significantly associated with poor survival. ${ }^{48}$ In 2009, we analyzed a cohort of 447 surgically resected NSCLC for EGFR and MET gene copy number using fluorescence in situ hybridization. In this study, we observed that MET amplification is a relatively rare phenomenon in NSCLC, occurring in approximately $4 \%$ of cases. ${ }^{47}$ Interestingly, patients with a mean of five or more $M E T$ gene copies had a significantly worse survival than individuals with a low increase in $M E T$ gene copy number (mean below five), demonstrating that MET is a negative prognostic factor in NSCLC. ${ }^{47}$ In the last few years, growing interest has been focused on the impact of increased $M E T$ gene copy number in the setting of EGFR-mutant patients. Indeed, MET amplification is responsible for acquired resistance to EGFR tyrosine kinase inhibitors in up to $20 \%$ of EGFR-mutant patients, ${ }^{20,21,49,50}$ while in EGFR tyrosine kinase inhibitor-naïve patients, $M E T$ amplification occurs in less than $5 \%$ of cases. ${ }^{47}$ Coamplification of both $M E T$ and $E G F R$ is a very rare event, occurring in less than $1 \%$ of cases. ${ }^{47,51}$ In a previous experience, we observed that $M E T$ amplification levels detected in EGFR tyrosine kinase inhibitor-naïve patients were generally lower than those observed in cell lines with acquired resistance to EGFR tyrosine kinase inhibitors. ${ }^{51}$ Based on these findings, we supposed that high levels of MET amplification, known to be associated with gefitinib resistance in vitro, rarely occurs in untreated NSCLC, irrespective of EGFR status, and may develop only under therapeutic pressure, leading to the conclusion that, in EGFR tyrosine kinase inhibitor-naïve patients, the level of genomic gain for MET is not increased enough to impact the response to tyrosine kinase inhibitors. These findings suggest that anti- MET strategies could be more effective in patients resistant to EGFR tyrosine kinase inhibitors than in EGFR TKI naïve. ${ }^{51}$

Finally, another mechanism responsible for MET dysregulation is gene mutation, an event occurring in approximately 5\%-10\% of NSCLCs. ${ }^{43,52-56}$ Several different $M E T$ mutations have been described in sporadic human cancer, including papillary renal cell carcinoma, ${ }^{52}$ and gastric and lung cancers. ${ }^{53-56}$ Distribution of $M E T$ mutations varies widely across ethnic and racial lines, with the highest frequency occurring in East Asians, ${ }^{57}$ while according to the type of mutation, they occur mainly in the non-tyrosine kinase domain followed by the juxtamembrane and sema domain. ${ }^{43,54-56}$ Intriguingly, the presence of mutations has been preferentially found in metastatic lesions compared with primary lesions. ${ }^{58}$ All these and other mechanisms of MET/HGF axis activation has been described in detail elsewhere. ${ }^{59-61}$

\section{Targeting MET}

There are at least four possible strategies that are useful for blockade of the HGF/MET pathway, ie, agents interfering with HGF binding to MET, anti-MET monoclonal antibodies, small molecule MET kinase inhibitors, and small molecule downstream pathway inhibitors of STAT3 ${ }^{59-63}$ More interestingly, data from preclinical studies suggest that the modality of $\mathrm{HGF} / \mathrm{MET}$ activation, such as autocrine/paracrine stimulation, gene amplification, or mutation, is crucial to be able to predict the class of agents that can effectively interrupt the signaling pathway. A list of anti-MET agents currently under investigation in NSCLC clinical trials is shown in Table 1.

Table I Hepatic growth factor/mesenchymal-epidermal transition axis inhibitors in active studies of non-small cell lung cancer

\begin{tabular}{|c|c|c|c|}
\hline Agent & Target & Type & Development phase \\
\hline \multicolumn{4}{|l|}{ Ligand antagonists } \\
\hline Ficlatuzumab (AV-299) & HGF & Monoclonal antibody & I and II \\
\hline Rilotumumab (AMG-I02) & HGF & Monoclonal antibody & II \\
\hline TAK-70I & HGF & Monoclonal antibody & I \\
\hline \multicolumn{4}{|l|}{ Receptor inhibitors } \\
\hline Onartuzumab (OA5D5) & MET & Monoclonal antibody & II and III \\
\hline \multicolumn{4}{|l|}{ Receptor TKIs } \\
\hline Tivantinib (ARQ-197) & MET & Non-ATP competitive TKI & II and III \\
\hline Cabozantinib (XL-184) & MET, RET, VEGFRI-3, KIT, FLT3, TIE2 & ATP competitive TKI & II \\
\hline Foretinib $(X L-880)$ & MET, RON, VEGFRI-3, PDGFR, KIT, FLT3, TIE2 & ATP competitive TKI & II \\
\hline Crizotinib (PF-0234I066) & MET, ALK & ATP competitive TKI & II and III \\
\hline MGCD-265 & MET, RON, VEGFRI-2, PDGFR, KIT, FLT3, TIE2 & ATP competitive TKI & II \\
\hline
\end{tabular}

Abbreviations: ALK, anaplastic lymphoma kinase; ATP, adenosine triphosphate; FLT3, fms-related tyrosine kinase 3; HGF, hepatocyte growth factor; MET, mesenchymalepidermal transition; PDGFR, platelet-derived growth factor receptor; RET, rearranged during transfection; TKI, tyrosine kinase inhibitor; VEGFR, vascular endothelia growth factor receptor. 


\section{HGF antagonists}

HGF antagonists prevent interaction between the ligand and receptor. HGF has two MET binding sites, one with high affinity and one with low affinity, accessible only to HGF and essential for MET dimerization and activation. ${ }^{62}$ NK2 is a truncated protein product of a natural alternative HGF mRNA transcript that competitively antagonizes growth stimulated by full length HGF. ${ }^{64}$ However, the potential antioncogenic efficacy of NK2 was found to be compromised by its intrinsic mitogenic activity, which enhanced HGF-driven metastasis in mouse models. ${ }^{65}$

NK4 is a longer truncated isoform of full length HGF proven to be a complete competitive antagonist of HGFcMET signaling in preclinical models, and has been tested by administration of the purified protein or as gene therapy. ${ }^{66-69}$ Unexpectedly, NK4 has been reported to inhibit angiogenesis induced by secreted factors, such as vascular endothelial growth factor receptor (VEGF) and basic fibroblast growth factor, and this angioinhibitory activity is independent of its action as an HGF antagonist. ${ }^{67}$ Importantly, NK4 protein and NK4 gene therapy have been shown to inhibit tumor invasion, metastasis, and angiogenesis, as demonstrated in in vivo models of colorectal and pancreatic cancers. ${ }^{67}$ Nevertheless, despite an exciting scenario for clinical development of such agents, no final reports of further drug development, activity, or safety are available as yet. ${ }^{69}$

\section{Onartuzumab}

Blockade of the HGF/MET cascade can be achieved successfully using antibodies directed against the extracellular domain of MET. Activity of monoclonal antibodies against MET was first demonstrated in preclinical models of glioblastoma, and pancreatic, gastric, and breast cancers, where tumor growth is sustained by autocrine or paracrine stimulation of the HGF/MET axis. ${ }^{70-72}$

Onartuzumab (MetMab ${ }^{\circledR}$, Genentech, Roche, Basel, Switzerland) is a fully humanized monoclonal antibody. Unlike classical bivalent monoclonal antibodies, its onearmed structure permits binding to the extracellular domain, thus avoiding receptor dimerization. Initial data on the safety and activity of onartuzumab administered intravenously every two or three weeks alone or in combination with bevacizumab were reported in two Phase I trials. ${ }^{73,74}$ In 2011, Spigel et al presented the results of a randomized Phase II study comparing onartuzumab + erlotinib versus erlotinib alone in 128 pretreated patients with NSCLC. ${ }^{75}$ The two coprimary endpoints of the study were progression-free survival in the entire population and progression-free survival in patients with high MET expression, defined as $\geq 50 \%$ of tumor cells staining moderately or strongly for MET by immunohistochemistry. Although the study did not meet the primary endpoint in the whole population, the risk of progression was significantly lower in patients with high MET expression (progression-free survival 3.0 versus 1.5 months; hazards ratio $0.47 ; P=0.002$ ). Intriguingly, a potentially detrimental effect in the experimental arm was observed for patients with low MET expression. Overall, these data suggested that onartuzumab in combination with erlotinib could be more effective than erlotinib alone in pretreated patients with NSCLC and high MET expression. A confirmatory Phase III study is currently ongoing.

\section{Antibodies against HGF}

Several monoclonal antibodies against HGF have been evaluated for their ability to prevent interaction of HGF with MET and consequently inhibit MET activation and the downstream cascade. ${ }^{76-78}$ In HGF/MET loop-dependent xenograft models, different anti-HGF antibodies demonstrated activity when used alone or in combination with chemotherapy. ${ }^{78}$

Ficlatuzumab (AV 299, Aveo Pharmaceuticals Inc, Cambridge, MA, USA) is a potent high-affinity HGF blocker. Since its initial development, it has been evaluated in combination with erlotinib or gefitinib in patients with pretreated advanced NSCLC. ${ }^{79,80}$ Results emerging from these trials indicated a favorable toxicity profile and interesting activity in five of the 12 treated patients. ${ }^{79}$ In a small group of Asian patients with unresectable and pretreated NSCLC, a combination of gefitinib and ficlatuzumab showed a promising response rate of $33 \%$ with manageable toxicity. ${ }^{80}$ On this basis, Asian researchers designed a randomized Phase II trial comparing standard gefitinib versus the combination of gefitinib and ficlatuzumab in 188 never-smokers or lightformer smokers with lung adenocarcinoma. The primary end point was efficacy in terms of response rate. The study failed to demonstrate a significant increase in overall response rate in favor of the experimental arm. Nevertheless, exploratory analyses revealed a significant improvement in survival for patients with high stromal HGF levels treated with the combination, while a non-significant trend favoring survival was noted for patients who were immunohistochemically MET-positive and had wild-type EGFR tumors. ${ }^{81}$

Rilotumumab (AMG 102, Amgen, Thousand Oaks, CA, USA) is a fully humanized monoclonal antibody that neutralizes HGF/SF. ${ }^{82}$ Early Phase I studies explored the safety of this new drug alone or in combination with other targeted agents, such as motesanib or bevacizumab. Overall, these 
studies highlighted a moderate incidence of adverse events, mainly fatigue, nausea/vomiting, and hypertension..$^{83,84}$ However, rilotumumab failed to demonstrate efficacy in a Phase II trial conducted in unselected patients with recurrent glioblastoma multiforme. ${ }^{85}$

Another anti-HGF antibody recently introduced into early-phase development is TAK $701 .^{86}$

In EGFR-mutant/HGF-expressing human clones, the combination of TAK 701 and gefitinib produced a marked inhibition of MET, EGFR, and Akt. ${ }^{87}$ Additional studies are needed to define the role of this compound.

\section{MET tyrosine kinase inhibitors}

The catalytic activity of MET can be blocked by small molecule inhibitors that generally compete for the adenosine triphosphate (ATP) binding site in the tyrosine kinase domain of MET, thus preventing the downstream signaling cascade. From a practical point of view, MET tyrosine kinase inhibitors belong to two main categories, depending on their specificity for MET or for other targets, such as VEGFR, platelet-derived growth factor receptor, fms-like tyrosine kinase 3 (FLT3), RON, and AXL. Use of a tyrosine kinase inhibitor seems to be particularly effective in tumors where MET activation is ligand-independent (ie, gene amplification or mutation). ${ }^{55,59,88-91}$

\section{Selective inhibitors}

Tivantinib (ARQ 197, ArQule ${ }^{\circledR}$, Daiichii-Sankyo, Bethlehem, PA, USA) is an oral small molecule first defined as a proapoptotic agent and subsequently found to have specificity as an anti-MET compound. ${ }^{92}$ Indeed, tivantinib acts by binding to a non-phosphorylated form of MET, locking it in an inactive state. ${ }^{93}$ Preclinical in vitro and in vivo experience as well as Phase I dose-escalation studies suggested its potential activity in different types of cancer. ${ }^{92-95}$ In the ARQ-197-101 and ARQ-197-103 studies, ${ }^{94,95}$ respectively, 79 and 51 heavily pretreated patents with a broad spectrum of solid malignancies received increasing doses of tivantinib, ranging from $10 \mathrm{mg}$ to $400 \mathrm{mg}$ twice daily. According to the dose-limiting toxicities (mainly febrile neutropenia and grade 3 mucositis) observed in the ARQ-197-103 trial, $360 \mathrm{mg}$ twice daily emerged in both trials as the recommended dose to use in Phase II studies. Interest in combining dual EGFR-MET inhibition in the clinical setting led to exploration of the feasibility of a combination of erlotinib and tivantinib. In the ARQ-197-111 trial, 32 patients with advanced solid tumors (of which $25 \%$ were NSCLC) were exposed to erlotinib at the standard dose of $150 \mathrm{mg}$ daily and oral tivantinib in an escalating fashion. ${ }^{96}$
Although the maximum tolerated dose was not reached, the safe dose of tivantinib for use in this combination was identified to be $360 \mathrm{mg}$ twice daily. More interestingly, six of eight patients with NSCLC achieved a stable disease. In 2011, Sequist et al published the final results of a randomized Phase II trial in which 167 pretreated (with at least one chemotherapy regimen but not with erlotinib) patients with NSCLC were randomly assigned to erlotinib monotherapy or to a combination of erlotinib and tivantinib, with the aim of demonstrating an improvement in progression-free survival in favor of the experimental arm. ${ }^{97}$ Subjects enrolled in the combination arm did not have a significantly higher probability of response (10\% versus $7 \%$ ), with no evidence of increased adverse events. The study did not reach its primary endpoint of progression-free survival in the entire population (3.8 months versus 2.3 months for the experimental arm and standard arm, respectively), but a trend toward survival was observed in non-squamous histology $(70 \%$ of the overall cohort) and in $K R A S$-mutant patients (14\% of the overall cohort), while the presence of EGFR mutations seemed not to affect the outcome. Unfortunately, the Phase III MARQUEE study conducted in a larger cohort of patients with advanced chemotherapy-refractory non-squamous NSCLC ${ }^{98}$ failed to replicate the previous findings. On October 2, 2012, a press release from the company announced early interruption of this trial following a planned interim analysis in the intent-to-treat population that showed no survival gain for patients receiving the two drugs. It is important to note that the patients in this study were not selected based on biological characteristics, providing a potential explanation for the failure of this trial.

Several further selective MET inhibitors are under evaluation in solid tumors, including PF04217903, AMG 337, and INCB028060. Early data suggest that these agents are potentially effective and Phase I studies are ongoing. ${ }^{99-104}$

\section{Non-selective inhibitors}

Crizotinib (PF 02341066, Xalkori ${ }^{\circledR}$, Pfizer, Mission, KS, USA) is a multitarget receptor tyrosine kinase inhibitor, and was initially synthesized as a MET inhibitor. ${ }^{105,106}$ In the Phase I trial (A8081001), an enriched cohort of 25 patients carrying a wide range of MET alterations received crizotinib, but impressive tumor shrinkage was only observed in MET-amplified tumors, such as NSCLC, gastroesophageal carcinoma, and glioblastoma. ${ }^{88-91}$ However, the occurrence of similarly dramatic responses in NSCLC cases harboring an ALK rearrangement shifted the enthusiasm of researchers towards clinical development of the drug in this molecularly defined setting. ${ }^{16-18}$ 
Other non-selective tyrosine kinase inhibitors targeting MET, RET, VEGF, KIT, FLT3, and RON, such as cabozantinib (XL184, Exelixis, San Francisco, CA, USA), ${ }^{107}$ foretinib (XL880, Exelixis), ${ }^{108,109}$ and golvatinib (E7050, Eisai, Tokyo, Japan $)^{110,111}$ have been extensively evaluated, and several Phase I-III studies of these new agents are currently ongoing in patients with different type of malignancies such as gastric and medullary thyroid cancer, glioblastoma, and renal cell carcinoma.

Cabozantinib is an oral multitarget inhibitor of MET, VEGFR, FLT3, and KIT. Like tivantinib, cabozantinib has been evaluated in combination with erlotinib in patients with NSCLC and acquired resistance to erlotinib. ${ }^{112,113}$ In a Phase $\mathrm{Ib} / \mathrm{II}$ trial, 54 patients with NSCLC received a combination of these two drugs in a $3+3$ design using combination doses across five cohorts in two parallel arms. No unexpected side effects were observed, and the most frequent grade 3/4 adverse events were diarrhea, fatigue, dyspnea, and hypoxia. Among the 36 patients assessable for response, six had a $\geq 30 \%$ reduction in tumor size, including three who achieved a partial response, while prolonged stable disease for more than four months has been observed in some cases; notably, among the responders, one had a $M E T$ amplification and among patients with long-lasting tumor stabilization, one harbored the EGFR T790M mutation. ${ }^{113}$ The activity and safety of cabozantinib $100 \mathrm{mg}$ daily was further evaluated in a large randomized Phase II discontinuation trial conducted in 483 patients with nine different tumor types, including NSCLC. Grade 3 fatigue, hand-foot skin reaction, and hypertension were the main class effects reported, while antitumor activity was observed across all tumor types. ${ }^{114}$ Interestingly, in the NSCLC cohort $(n=60)$, tumor regression was seen in $64 \%$ of evaluable patients, with six $(13 \%)$ patients experiencing a partial response; notably, some of the responders had a known driver mutation at baseline (three EGFR mutations, three KRAS mutations), while non-responders did not. ${ }^{114}$ Nevertheless, the small sample size does not allow definitive conclusions concerning the effect of EGFR or KRAS mutations on response.

Foretinib is an ATP-competitive dual inhibitor of MET and VEGFR. Two Phase I studies with different schedules of administration have been done in patients with advanced solid tumors. ${ }^{108,109}$ In both trials, hypertension, diarrhea, fatigue, vomiting, and proteinuria were the main toxicities observed. Based on the observation that combination of foretinib with an anti-HER agent (erlotinib or lapatinib) produced a remarkable decrease in MET, HER1, HER2, HER3, Akt phosphorylation in cell lines, a Phase I/II study of erlotinib with or without foretinib is now under way. ${ }^{115,116}$
Golvatinib also inhibits MET and VEGFR, and in vitro models have demonstrated the ability of this agent to prevent emergence of resistance to EGFR tyrosine kinase sustained by HGF. ${ }^{110}$ A Phase I study in adults with advanced solid tumors established $400 \mathrm{mg}$ daily as the recommended dose, while fatigue, diarrhea, nausea/vomiting, and increased transaminase levels were the typical toxicities. ${ }^{111}$

Early clinical trials of MGC D265 and ANG707, two of the newest non-selective MET inhibitors, have just started recruitment, and it is planned to give these agents as monotherapy or in combination with erlotinib. ${ }^{117,118}$

\section{Downstream signaling pathway}

OPB-31121 is a small molecule that inhibits interleukin-6induced phosphorylation of STAT3, leading to disruption of the JAK/STAT signaling pathway. ${ }^{63}$ In a Phase I doseescalation study in patients with advanced solid tumors, including lung cancer, OPB-31121 produced disease stabilization in $47 \%$ of cases, with a favorable toxicity profile. ${ }^{63}$ The promising antitumor activity of this compound warrants further investigation.

\section{MET as a modulator of sensitivity to ionizing radiation}

As previously discussed, activation of MET promotes epithelial-mesenchymal transition, hypoxia-related angiogenesis, and invasiveness of cancer, and a growing amount of data have demonstrated that these phenomena are closely related to resistance to ionizing radiation. . $^{59-61,119-126}$

Several preclinical investigations have suggested that MET was upregulated in irradiated cancer cells and how this event was influenced by HGF as well as by radiation dose and duration. ${ }^{119-122}$ In glioblastoma multiforme cell lines, radiation enhanced HGF levels, thus determining radioresistance. ${ }^{122}$ The same has been observed in neuroblastoma cells, where higher levels of HGF mRNA were founded in irradiated cells than in those not exposed to radiation; ${ }^{123}$ interestingly, the invasiveness of neuroblastoma cells was higher in the presence of elevated MET expression at baseline. ${ }^{123}$ In pancreatic cancer, increasing doses of radiation can stimulate MET expression and cancer invasiveness under HGF pressure. ${ }^{122}$ Recently, Li et al showed in a preclinical model of NSCLC that the combination of radiation therapy and MET inhibition with AMG-458 synergistically increased apoptosis in cells with constitutive phosphorylation of MET. ${ }^{124}$

From a clinical point of view, in patients with oropharynx squamous carcinoma and treated with curative radiotherapy, MET overexpression negatively affected local failure 
free-survival, while HGF levels were inversely correlated with failure-free survival. ${ }^{125}$ Further, high MET levels, assessed by immunohistochemistry in nasopharyngeal carcinoma specimens, identified a subgroup of patients with worse outcome after local radiotherapy (five-year survival rate $48 \%$ versus $84 \%$ for high and low MET levels, respectively). ${ }^{126}$

These data demonstrate that activation of MET is related to irradiation highlighting the potential role of MET inhibition in overcoming resistance to radiotherapy.

\section{Discussion}

During the last few years, advances in our knowledge of cancer biology have led to the development of strategies interfering with activation of the MET pathway. Nevertheless, at the present time, no anti-MET agent is available in clinical practice outside clinical trials, so the role of these agents remains promising but still undefined.

A critical issue concerns the biological selection of patients who are candidates for an anti-MET strategy and identification of the ideal predictive biomarker. It is important to highlight that none of the aforementioned trials included molecular selection of patients. ${ }^{75,80,81,88-91,97,115}$ Preplanned subgroup analyses suggest that overexpression of MET assessed by immunohistochemistry could be useful for predicting the efficacy of anti-MET monoclonal antibodies. ${ }^{75,127}$ Indeed, onartuzumab increased progression-free survival in patients with high MET expression, but had a detrimental effect in those with low or negative MET expression. ${ }^{75}$ Notably, in advanced gastric cancer, addition of rilotumumab to chemotherapy produced a higher response rate and longer survival than chemotherapy alone in patients with high MET expression. ${ }^{127}$ On the other hand, the results from trial A8081001 clearly demonstrated that crizotinib, a selective MET and ALK inhibitor, is active in NSCLC as well as in other malignancies only in presence of MET gene amplification. ${ }^{88-91}$ Overall, these data indicate that anti-MET therapy might be effective only in molecularly defined subgroups of patients.

Another hot topic is the optimal timing of introduction of an anti-MET agent in the treatment algorithm. Because of synergism with the EGFR pathway, the vast majority of trials have tested different anti-MET compounds in EGFR tyrosine kinase inhibitor-resistant or chemorefractory settings, and in this context, MET inhibition seemed to be potentially effective. ${ }^{75,80,81,88-91,97,98,115}$ Nevertheless, use of an anti-MET drug as front-line treatment should be considered in selected cases. In tumors for which MET dysregulation represents a real driver, probably the best way to maximize the therapeutic effect of anti-MET agents would be introduction of the drug early in the course of the disease, such as in the front-line setting. As a proof of concept, dramatic tumor regression in response to an anti-MET agent has been described in some MET-amplified NSCLC and gastric cancer cell lines, similar to that observed in EGFR-mutant clones exposed to erlotinib or gefitinib. ${ }^{128,129}$ Unfortunately, at the present time, no study has explored the role of anti-MET agents in the first-line setting for patients with NSCLC.

Finally, whether anti-MET compounds are more effective when administered as single agents or in combination with other drugs remains undefined. Earlier in this review, we reported that simultaneous inhibition of the MET and HER pathways using onartuzumab and or a MET tyrosine kinase inhibitor plus an anti-EGFR agent appeared to be the most appropriate strategy for overcoming acquired resistance. ${ }^{20,21}$ Crosstalk between MET/HGF and other cellular signal transduction pathways, such as RON, FAS, HER2, and integrins, offers the opportunity to explore different therapeutic combinations. ${ }^{59,61}$ Recently, a novel link between MET and angiogenesis has been identified. Preclinical studies indicated that MET expression and activation are enhanced in the presence of hypoxia. ${ }^{130,131}$ As a consequence of antiangiogenic therapy, a decrease in tumor vascularization and hypoxic stress led to MET-dependent proliferation, and a combination of anti-VEGF and anti-MET therapies could prevent the occurrence of this event. ${ }^{130,131}$ Indeed, a Phase III trial comparing the anti-VEGF monoclonal antibody, bevacizumab, administered alone or in combination with onartuzumab is ongoing in glioblastoma, which is one of the most vascularized malignancies. ${ }^{132}$

\section{Conclusion}

In summary, due to its central role in the proliferation and metastasis of cancer, MET has recently emerged as a promising target in NSCLC. The development of MET-targeted agents offers the opportunity to improve outcomes for patients, but careful biological selection remains crucial for better definition of which patients will benefit most from such treatment, and emerging data reinforce the conviction that target selection is mandatory. Results from ongoing trials are eagerly awaited because they might pave the path to new molecularly targeted treatments for NSCLC and new hope for our patients.

\section{Acknowledgment}

Supported in part by AIRC (Associazione Italiana per la Ricerca sul Cancro) and AOT (Associazione Oncologia Traslazionale). 


\section{Disclosure}

The authors report no conflicts of interest in this work.

\section{References}

1. Schiller JH, Harrington D, Belani CP, et al. Comparison of four chemotherapy regimens for advanced non-small-cell lung cancer. $N$ Engl J Med. 2002;346(2):92-98.

2. De Bono JS, Ashworth A. Translating cancer research into targeted therapeutics. Nature. 2010;467(7315):543-549.

3. Pez JG, Jänne PA, Lee JC, et al. EGFR mutations in lung cancer: correlation with clinical response to gefitinib therapy. Science. 2004;304(5676):1497-1500.

4. Pao W, Miller V, Zakowski M, et al. EGF receptor gene mutations are common in lung cancers from "never smokers" and are associated with sensitivity of tumors to gefitinib and erlotinib. Proc Natl Acad Sci U S A. 2004;101(36):13306-13311.

5. Soda M, Takada S, Takeuchi K, et al. Identification of the transforming EML4-ALK fusion gene in non-small cell lung cancer. Nature. 2007;448(7153):561-566.

6. Shaw AT, Yeap BY, Mino-Kenudson M, et al. Clinical features and outcome of patients with non-small-cell lung cancer who harbor EML4ALK. J Clin Oncol. 2009;27(26):4247-4253.

7. Shaw AT, Engelman JA. ALK in lung cancer: past, present, and future. J Clin Oncol. 2013;31(8):1105-1111.

8. MokTS, Wu YL, Thongprasert S, et al. Gefitinib or carboplatin-paclitaxel in pulmonary adenocarcinoma. N Engl J Med. 2009;361(10): 947-957.

9. Rosell R, Carcereny E, Gervais R, et al. Erlotinib versus standard chemotherapy as first-line treatment for European patients with advanced EGFR mutation-positive non-small-cell lung cancer (EURTAC): a multicentre, open-label, randomised phase 3 trial. Lancet Oncol. 2012;13(3):239-246.

10. Han JY, Park K, Kim SW, et al. First-SIGNAL: first-line single-agent iressa versus gemcitabine and cisplatin trial in never-smokers with adenocarcinoma of the lung. J Clin Oncol. 2012;30(10):1122-1128.

11. Mitsudomi T, Morita S, YatabeY, et al. Gefitinib versus cisplatin plus docetaxel in patients with non-small-cell lung cancer harbouring mutations of the epidermal growth factor receptor (WJTOG3405): an open label, randomised phase 3 trial. Lancet Oncol. 2010;11(2): 121-128.

12. Maemondo M, Inoue A, Kobayashi K, et al. Gefitinib or chemotherapy for non-small-cell lung cancer with mutated EGFR. $N$ Engl $J$ Med. 2010;362(25):2380-2388.

13. Zhou C, Wu YL, Chen G, et al. Erlotinib versus chemotherapy as first-line treatment for patients with advanced EGFR mutation-positive non-smallcell lung cancer (OPTIMAL, CTONG-0802): a multicentre, open-label, randomised, phase 3 study. Lancet Oncol. 2011;12(8): 735-742.

14. Yang JC, Schuler MH, Yamamoto N, et al. LUX-Lung 3: a randomized, open-label, phase III study of afatinib versus pemetrexed and cisplatin as first-line treatment for patients with advanced adenocarcinoma of the lung harboring EGFR-activating mutations. J Clin Oncol. 2012; 30 Suppl:Abstr LBA7500.

15. Mok TS, Lee JS, Zhang L, et al. Biomarkers analyses and overall survival (OS) from the randomized, placebo-controlled, phase 3, FASTACT-2 study of intercalated erlotinib with first-line chemotherapy in advanced non-small cell lung cancer (NSCLC). Ann Oncol. 2012; 23 Suppl 9:Abstr 12260.

16. Kwak EL, Bang YJ, Camidge R, et al. Anaplastic lymphoma kinase inhibition in non-small cell lung cancer. N Engl J Med. 2010;363(18): 1693-1703.

17. Camidge R, Bang YJ, Kwak EL, et al. Activity and safety of crizotinib in patients with ALK-positive non-small-cell lung cancer: updated results from a phase 1study. Lancet Oncol. 2012;13(10): 1011-1019.

18. Shaw AT, Kim DW, Nakagawa K, et al. Phase III study of crizotinib versus pemetrexed or docetaxel chemotherapy in patients with advanced ALK-positive non-small-cell-lung cancer (NSCLC) (Profile 1007). Ann Oncol. 2012;23 Suppl 9:Abstr LBA1_PR.
19. Gridelli C, Ciardiello F, Gallo C, et al. First-line erlotinib followed by second-line cisplatin-gemcitabine chemotherapy in advanced nonsmall-cell lung cancer: the TORCH randomized trial. J Clin Oncol. 2012;30(24):3002-3011.

20. Sequist LV, Waltman AW, Dias-Santagata D, et al. Genotyping and histological evolution of lung cancers acquiring resistance to EGFR inhibitors. Sci Transl Med. 2011;3(75):75ra26.

21. Engelman JA, Zejnullahu K, Mitsudomi T, et al. MET amplification leads to gefitinib resistance in lung cancer by activating ERBB3 signaling. Science. 2007;316(5827):1039-1043.

22. Xu Y, Kikuchi E, Xu C, et al. Combined EGFR/MET or EGFR/ HSP90 inhibition is effective in the treatment of lung cancers codriven by mutant EGFR containing T790M and MET. Cancer Res. 2012;72(13):3302-3311.

23. Bottaro DP, Rubin JS, Faletto DL, et al. Identification of the hepatocyte growth factor receptor as the c-met proto-oncogene product. Science. 1991;251(4995):802-804.

24. Birchmeier C, Gherardi E. Developmental roles of HGF/SF and its receptor, the c-Met tyrosine kinase. Trends Cell Biol. 1998;8(10):404-410.

25. Camoglio PM. Pathway specificity for Met signalling. Nat Cell Biol. 2001;3(7):E161-E162.

26. Takayama H, La Rochelle WJ, Anver M, Bockman DE, Merlino G. Scatter factor/hepatocyte growth factor as a regulator of skeletal muscle and neural crest development. Proc Natl Acad Sci U SA. 1996;93(12): 5866-5871.

27. Bussolino F, Di Renzo MF, Ziche M, et al. Hepatocyte growth factor is a potent angiogenic factor which stimulates endothelial cell motility and growth. J Cell Biol. 1992;119(3):629-641.

28. Schmidt C, Bladt F, Goedecke S, et al. Scatter factor/hepatocyte growth factor is essential for liver development. Nature. 1995;373(6516): 699-702.

29. Trusolino L, Camoglio M. Scatter-factor and semaphorin receptors: cell signalling for invasive growth. Nat Rev Cancer. 2002;2(4):289-300.

30. Rabkin R, Fervenza F, Tsao T, et al. Hepatocyte growth factor receptor in acute tubular necrosis. J Am Soc Nephrol. 2001;12(3):531-540.

31. Okada H, Kalluri R. Cellular and molecular pathways that lead to progression and regression of renal fibrogenesis. Curr Mol Med. 2005;5(5): 467-474.

32. Moransard M, Sawitzky M, Fontana A, Suter T. Expression of the HGF Receptor c-met by macrophages in experimental autoimmune encephalomyelitis. Glia. 2010;58(5):559-571.

33. Tsao MS, Liu N, Chen JR, et al. Differential expression of met/ hepatocyte growth factor receptor in subtypes of non-small cell lung cancer. Lung Cancer. 1998;20(1):1-16.

34. Koochekpour S, Jeffers M, Rulong S, et al. Met and hepatocyte growth factor/scatter factor expression in human gliomas. Cancer Res. 1997;57(23):5391-5398.

35. Hara T, Ooi A, Kobayashi M, et al. Amplification of c-myc, K-sam, and c-met in gastric cancers: detection by fluorescence in situ hybridization. Lab Invest. 1998;78(9):1143-1153.

36. Miller CT, Lin L, Casper AM, et al. Genomic amplification of MET with boundaries within fragile site FRA7G and upregulation of MET pathways in esophageal adenocarcinoma. Oncogene. 2006;25(3):409-418.

37. Sawada K, Radjabi AR, Shinomiya N, et al. C-Met overexpression is a prognostic factor in ovarian cancer and an effective agent for inhibition of peritoneal dissemination and invasion. Cancer Res. 2007;67(4): $1670-1679$.

38. Nagy J, Curry GW, Hillan KJ, et al. Hepatocyte growth factor/scatter factor expression and c-met in primary breast cancer. Surg Oncol. 1996;5(1):15-21.

39. Lubensky IA, Schmidt L, Zhuang Z, et al. Hereditary and sporadic papillary renal carcinomas with c-met mutations share a distinct morphological phenotype. Am J Pathol. 1999;155(2):517-526.

40. Ueki T, Fujimoto J, Suzuki T, Yamamoto H, Okamoto E. Expression of hepatocyte growth factor and its receptor, the c-met proto-oncogene, in hepatocellular carcinoma. Hepatology. 1997;25(4):619-623. 
41. Danilkovitch-Miagkova A, Zbar B. Dysregulation of Met receptor tyrosine kinase activity in invasive tumors. J Clin Invest. 2002;109(7): 863-867.

42. Oliviero M, Rizzo M, Madeddu R, et al. Overexpression and activation of hepatocyte growth factor/scatter factor in human non-small-cell lung carcinomas. Br J Cancer. 1996;74(12):1862-1868.

43. Ma PC, Tretiakova MS, MacKinnon AC, et al. Expression and mutational analysis of MET in human solid cancers. Genes Chromosomes Cancer. 2008;47(12):1025-1037.

44. Ichimura E, Maeshima A, Nakajima T, et al. Expression of c-met/ HGF receptor in human non small cell lung carcinomas in vitro and in vivo and its prognostic significance. Jpn J Cancer Res. 1996;87(10): 1063-1069.

45. Garcia S, Dalès JP, Charafe-Jauffret E, et al. Poor prognosis in breast carcinomas correlates with increased expression of targetable CD146 and c-Met and with proteomic basal-like phenotype. Hum Pathol. 2007; 38(6):830-841.

46. Takanami I, Tanana F, Hashizume T, et al. Hepatocyte growth factor and c-Met/hepatocyte growth factor receptor in pulmonary adenocarcinomas: an evaluation of their expression as prognostic markers. Oncology. 1996;53(5):392-397.

47. Cappuzzo F, Marchetti A, Skokan M, et al. Increased MET gene copy number negatively affects survival of surgically resected non-small-cell lung cancer patients. J Clin Oncol. 2009;27(10):1667-1674.

48. Okuda K, Sasaki H, Yukiue H, et al. Met gene copy number predicts the prognosis for completely resected non-small cell lung cancer. Cancer Sci. 2008;99(11):2280-2285.

49. Bean J, Brennan C, Shih J, et al. MET amplification occurs with or without T790M mutations in EGFR mutant lung tumors with acquired resistance to gefitinib or erlotinib. Proc Natl Acad Sci U S A. 2007;104(52):20932-20937.

50. Chen H, Mok T, Chen Z, et al. Clinicopathologic and molecular features of epidermal growth factor receptor T790M mutation and c-MET amplification in tyrosine kinase inhibitor-resistant Chinese non-small cell lung cancer. Pathol Oncol Res. 2009;15(4):651-658.

51. Cappuzzo F, Janne PA, Skokan M, et al. MET increased gene copy number and primary resistance to gefitinib therapy in non-small cell lung cancer patients. Ann Oncol. 2009;20(2):298-304.

52. Schmidt L, Duh FM, Chen F, et al. Germline and somatic mutations in the tyrosine kinase domain of the MET proto-oncogene in papillary renal carcinomas. Nat Genet. 1997;16(1):68-73.

53. Lee JH, Han SU, Cho H, et al. A novel germ line juxtamembrane MET mutation in human gastric cancer. Oncogene. 2000;19(43) 4947-4953.

54. Ma P, Kijima T, Maulik G, et al. c-MET mutational analysis in small cell lung cancer: novel juxtamembrane domain mutations regulating cytoskeletal functions. Cancer Res. 2003;63(19):6272-6281.

55. Ma PC, Jagadeeswaran R, Jagadeesh S, et al. Functional expression and mutations of c-Met and its therapeutic inhibition with SU11274 and small interfering RNA in non-small cell lung cancer. Cancer Res. 2005;65(4):1479-1488.

56. Onozato R, Kosaba T, Kuwano H, et al. Activation of MET by gene amplification or by splice mutations deleting the juxtamembrane domain in primary resected lung cancers. J Thorac Oncol. 2009;4(1):5-11.

57. Krishnaswamy S, Kanteti R, Duke-Cohan JS, et al. Ethnic differences and functional analysis of MET mutations in lung cancer. Clin Cancer Res. 2009;15(18):5714-5723.

58. Di Renzo MF, Olivero M, Martone T, et al. Somatic mutations of the MET oncogene are selected during metastatic spread of human HNSC carcinomas. Oncogene. 2000;19(12):1547-1555.

59. Blumenschein GR Jr, Mills GB, Gonzalez-Angulo AM. Targeting the hepatocyte growth factor-cMET axis in cancer therapy. J Clin Oncol. 2012;30(26):3287-3296.

60. Comoglio PM, Giordano S, Trusolino L. Drug development of MET inhibitors: targeting oncogene addiction and expedience. Nat Rev Drug Discov. 2008;7(6):504-516.
61. Gherardi E, Birchmeier W, Birchmeier C, Van de Wounde G. Targeting MET in cancer: rationale and progress. Nat Rev Cancer. 2012;12(2): 89-103.

62. Canadas I, Rojo F, Arumi-Uria M, et al. C-MET as a new therapeutic target for the development of novel anticancer drugs. Clin Transl Oncol. 2010;12(4):253-260.

63. Oh D, Han S, Kim TM, et al. A phase I, open-label, nonrandomized trial of OPB-31121, a STAT3 inhibitor, in patients with advanced solid tumors. J Clin Oncol. 2010;28 Suppl:Abstr e13056.

64. Chan AM, Rubin JS, Bottaro DP, et al. Identification of a competitive HGF antagonist encoded by an alternative transcript. Science. 1991;254(5036):1382-1385

65. Yu Y, Merlino G. Constitutive c-Met signaling through a nonautocrine mechanism promotes a metastasis in a transgenic transplantation model. Cancer Res. 2002;62(10):2951-2956.

66. Cecchi F, Rabe DC, Bottaro DP. Targeting the HGF/Met signalling pathway in cancer. Eur J Cancer. 2010;46(7):1260-1270.

67. Date K, Matsumoto K, Shimura H, Tanaka M, Nakamura T. HGF/NK4 is a specific antagonist for pleiotrophic actions of hepatocyte growth factor. FEBS Lett. 1997;420(1):1-6.

68. Kuba K, Matsumoto K, Date K, et al. HGF/NK4, a four-kringle antagonist of hepatocyte growth factor, is an angiogenesis inhibitor that suppresses tumor growth and metastasis in mice. Cancer Res. 2000;60(23):6737-6743.

69. Matsumoto K, Nakamura T. Nk4 gene therapy targeting HGF-met and angiogenesis. Front Biosci. 2008;13:1943-1951.

70. Martens T, Schmidt NO, Eckerich C, et al. A novel one-armed anti-cMet antibody inhibits glioblastoma growth in vivo. Clin Cancer Res. 2006;12(20 Pt 1):6144-6152.

71. Jin H, Yang R, Zheng Z, et al. Metmab, the one-armed $5 \mathrm{~d} 5$ anti-c-Met antibody, inhibits orthotopic pancreatic tumor growth and improves survival. Cancer Res. 2008;68(11):4360-4368.

72. Tseng JR, Kang KW, Dandekar M, et al. Preclinical efficacy of the c-Met inhibitor CE-355621 in a U87 MG mouse xenograft model evaluated by18F-FDG small-animal PET. J Nucl Med. 2008;49(1): 129-134.

73. Berinstein NL, Morse M, Kaufman H, et al. A phase I study of the safety and immunogenicity of a therapeutic vaccine, DPX-0907 in patients with advanced-stage ovarian, breast, or prostate cancer. J Clin Oncol. 2011;29 Suppl:Abstr e13050.

74. Moss RA, Bothos J, Patel P, et al. Complete results from phase I dose escalation study of MetMAb, a monovalent antagonist antibody to the receptor met, dosed as single agent and in combination with bevacizumab in patients with advanced solid malignancies. Ann Oncol. 2010;21:Abstr 504P.

75. Spigel DR, Ervin TJ, Ramlau R, et al. Final efficacy results from OAM4558 g, a randomized phase II study evaluating MetMAb or placebo in combination with erlotinib in advanced NSCLC. $J$ Clin Oncol. 2011;29 Suppl:Abstr 7505.

76. Burgess T, Coxon A, Meyer S, et al. Fully human monoclonal antibodies to hepatocyte growth factor with therapeutic potential against hepatocyte growth factor/c-Met-dependent human tumors. Cancer Res. 2006;66(3):1721-1729.

77. Kim KJ, Wang L, Su YC, et al. Systemic anti-hepatocyte growth factor monoclonal antibody therapy induces the regression of intracranial glioma xenografts. Clin Cancer Res. 2006;12(4): 1292-1298.

78. Jun HT, Sun J, Rex K, et al. AMG 102, a fully human anti-hepatocyte growth factor/scatter factor neutralizing antibody, enhances the efficacy of temozolomide or docetaxel in U-87 mg cells and xenografts. Clin Cancer Res. 2007;13(22 Pt 1):6735-6742.

79. Patnaik A, Weiss GJ, Papadopoulos K, et al. Phase I study of SCH 900105 (SC), an anti-hepatocyte growth factor (HGF) monoclonal antibody (MAb), as a single agent and in combination with erlotinib (E) in patients (pts) with advanced solid tumors. J Clin Oncol. 2010;28:Abstr 2525 . 
80. Tan E, Park K, Lim W, et al. A Phase 1b Study of ficlatuzumab (AV-299), an anti-hepatocyte growth factor monoclonal antibody, in combination with gefitinib in Asian patients with NSCLC. J Clin Oncol. 2011;29 Suppl:Abstr 7571.

81. Mok TS, Park K, Geater SL, et al. A randomized phase 2 study with exploratory biomarker analysis of ficlatuzumab a humanized hepatocyte growth factor inhibitory MAB in combination with gefitinib versus gefitinib in Asian patients with lung adenocarcinoma. Ann Oncol. 2012;23:Abstr 1198P.

82. Burgess TL, Sun J, Meyer S, et al. Biochemical characterization of AMG 102: a neutralizing, fully human monoclonal antibody to human and nonhuman primate hepatocyte growth factor. Mol Cancer Ther. 2010;9(2):400-409.

83. Gordon MS, Sweeney CS, Mendelson DS, et al. Safety, pharmacokinetics, and pharmacodynamics of AMG 102, a fully human hepatocyte growth factor-neutralizing monoclonal antibody, in a first-in-human study of patients with advanced solid tumors. Clin Cancer Res. 2010;16(2):699-710.

84. Rosen PJ, Sweeney CJ, Park DJ, et al. A phase Ib study of AMG 102 in combination with bevacizumab or motesanib in patients with advanced solid tumors. Clin Cancer Res. 2010;16(9):2677-2687.

85. Wen PY, Schiff D, Cloughesy TF, et al. A phase II study evaluating the efficacy and safety of AMG 102 (rilotumumab) in patients with recurrent glioblastoma. Neuro Oncol. 2011;13(4):437-446.

86. Okamoto W, Okamoto I, Tanaka K, et al. TAK-701, a humanized monoclonal antibody to hepatocyte growth factor, reverses gefitinib resistance induced by tumor- derived HGF in non-small cell lung cancer with an EGFR mutation. Mol Cancer Ther. 2010;9(10):2785-2792.

87. Jones SF, Cohen RB, Bendell JC, et al. Safety, tolerability, and pharmacokinetics of TAK-701, a humanized anti-hepatocyte growth factor (HGF) monoclonal antibody, in patients with advanced non hematologic malignancies: first-in-human phase I dose-escalation study. $J$ Clin Oncol. 2010;28 Suppl:Abstr 3081.

88. Tanizaki J, Okamoto I, Okamoto K, et al. MET tyrosine kinase inhibitor crizotinib (PF-02341066) shows differential antitumor effects in nonsmall cell lung cancer according to MET alterations. J Thorac Oncol. 2011;6(10):1624-1631.

89. Ou SH, Kwak EL, Siwak-Tapp C, et al. Activity of crizotinib (PF02341066), a dual mesenchymal-epithelial transition (MET) and anaplastic lymphoma kinase (ALK) inhibitor, in a non-small cell lung cancer patient with de novo MET amplification. J Thorac Oncol. 2011;6(5):942-946.

90. Lennerz JK, Kwak EL, Ackerman A, et al. MET amplification identifies a small and aggressive subgroup of esophagogastric adenocarcinoma with evidence of responsiveness to crizotinib. J Clin Oncol. 2011; 29(36):4803-4810.

91. Chi AS, Batchelor TT, Kwak EL, Clark JW, Wang DL. Radiographic and clinical improvement after treatment of a MET-amplified recurrent glioblastoma with a mesenchymal-epithelial transition inhibitor. $J$ Clin Oncol. 2012;30(3):e30-e33.

92. Munshi N, Jeay S, Li Y, et al. ARQ 197, a novel and selective inhibitor of the human c-Met receptor tyrosine kinase with antitumor activity. Mol Cancer Ther. 2010;9(6):1544-1553.

93. Jarvis LM. One pill, many uses. Chem Eng News. 2007;85:15-23.

94. Rosen LS, Senzer N, Mekhail T, et al. A phase I dose- escalation study of tivantinib (ARQ 197) in adult patients with metastatic solid tumors. Clin Cancer Res. 2011;17(24):7754-7764.

95. Yap TA, Olmos D, Brunetto AT, et al. Phase I trial of a selective c-MET inhibitor ARQ 197 incorporating proof of mechanism pharmacodynamic studies. J Clin Oncol. 2011;29(10):1271-1279.

96. Goldman JW, Laux I, Chai F, et al. Phase 1 dose-escalation trial evaluating the combination of the selective MET (mesenchymal-epithelial transition factor) inhibitor tivantinib (ARQ 197) plus erlotinib. Cancer. 2012;118(23):5903-5911

97. Sequist LV, von Pawel J, Garmey EG, et al. Randomized phase II study of erlotinib plus tivantinib versus erlotinib plus placebo in previously treated non-small-cell lung cancer. J Clin Oncol. 2011;29(24): $3307-3315$.
98. Scagliotti GV, Novello S, Schiller JH, et al. Rationale and design of MARQUEE: a phase III, randomized, double-blind study of tivantinib plus erlotinib versus placebo plus erlotinib in previously treated patients with locally advanced or metastatic, nonsquamous, non-smallcell lung cancer. Clin Lung Cancer. 2012;13(5):391-395.

99. Zou HY, Li Q, Lee JH, et al. Sensitivity of selected human tumor models to PF-04217903, a novel selective c-Met kinase inhibitor. Mol Cancer Ther. 2012;11(4):1036-1047.

100. ClinicalTrial.gov. A study of PF-04217903 in patients with advanced cancer. Available from: http://clinicaltrials.gov/show/NCT00706355. Accessed May 16, 2013.

101. ClinicalTrial.gov. NCT01253707. A Study of AMG 337 in subjects with advanced solid tumors. Available online: http://www.clinicaltrial.gov.

102. Koblish HK, Liu X, Hall L, et al. Preclinical in vivo characterization of INCB028060, a novel, potent and highly selective c-Met inhibitor. J Clin Oncol. 2008;26 Suppl:Abstr 14561.

103. Liu X, Wang Q, Yang G, et al. A novel kinase inhibitor, INCB28060, blocks c-MET-dependent signaling, neoplastic activities, and cross-talk with EGFR and HER-3. Clin Cancer Res. 2011;17(22):7127-7138.

104. Donehower RC, Scardina A, Hill M, et al. A phase I dose-escalation study of INCB028060, an inhibitor of c-MET receptor tyrosine kinase, in patients with advanced solid tumors. J Clin Oncol. 2011; 29 Suppl:Abstr 3091.

105. Cui JJ, Tran-Dubé M, Shen H, et al. Structure based drug design of crizotinib (PF-02341066), a potent and selective dual inhibitor of mesenchymal-epithelial transition factor (c-MET) kinase and anaplastic lymphoma kinase (ALK). J Med Chem. 2011;54(18):6342-6363.

106. Ou SH. Crizotinib: a novel and first-in-class multitargeted tyrosine kinase inhibitor for the treatment of anaplastic lymphoma kinase rearranged non-small cell lung cancer and beyond. Drug Des Devel Ther. 2011;5:471-485.

107. Yakes FM, Chen J, Tan J, et al. Cabozantinib (XL184), a novel MET and VEGFR2 inhibitor, simultaneously suppresses metastasis, angiogenesis, and tumor growth. Mol Cancer Ther. 2011;10(12):2298-2308.

108. Eder JP, Shapiro GI, Appleman LJ, et al. A phase I study of foretinib, a multi-targeted inhibitor of c-Met and vascular endothelial growth factor receptor 2. Clin Cancer Res. 2010;16(13):3507-3516.

109. Shapiro GI, McCallum S, Adams LM, et al. A Phase 1 dose-escalation study of the safety and pharmacokinetics of once-daily oral foretinib, a multi-kinase inhibitor, in patients with solid tumors. Invest New Drugs. 2013;31(3):742-750.

110. Wang W, Li Q, Takeuchi S, et al. Met kinase inhibitor E7050 reverses three different mechanisms of hepatocyte growth factor-induced tyrosine kinase inhibitor resistance in EGFR mutant lung cancer. Clin Cancer Res. 2012;18(6):1663-1671.

111. Toshihiko D, Takayuki Y, Nozomu F, et al. Phase I dose-finding study of golvatinib (E7050), a c-Met and Eph receptor targeted multi-kinase inhibitor, administered orally QD to patients with advanced solid tumors. J Clin Oncol. 2012;30 Suppl:Abstr 3079.

112. Nokihara H, Yamamoto N, Nakamichi S, et al. Molecular profile and anti-tumor activity in nonsmallcell lung cancer (NSCLC) patients (pts) in a phase 1study of cabozantinib (XL184) in Japan. Ann Oncol. 2012;23:Abstr 17O8PD.

113. Wakelee HA, Gettinger SN, Engelman JA, et al. A phase Ib/II study of XL184 (BMS 907351) with and without erlotinib in patients (pts) with non-small cell lung cancer (NSCLC). J Clin Oncol. 2010; 28 Suppl:Abstr 3017.

114. Hellerstedt BA, Edelman G, Vogelzang NJ, et al. Activity of cabozantinib (XL184) in metastatic NSCLC: results from a phase II randomized discontinuation trial (RDT). J Clin Oncol. 2012;30 Suppl:Abstr 7514.

115. Liu L, Shi H, Liu Y, et al. Synergistic effects of foretinib with HERtargeted agents in MET and HER1- or HER2-coactivated tumor cells. Mol Cancer Ther. 2011;10(3):518-530.

116. ClinicalTrials.gov. A Phase 3 study of telaprevir in combination with Pegasys $^{\circledR}$ and Copegus ${ }^{\circledR}$ in treatment-naive subjects with genotype 1 HCV. Available from: http://clinicaltrials.gov/show/NCT00627926. Accessed May 16, 2013. 
117. Bonfils C, Beaulieu N, Fournel M, et al. The combination of MGC D265, a MET/VEGFR inhibitor in clinical development, and erlotinib potently inhibits tumour growth by altering multiple pathways including glycolysis. Abstract 1790 presented at the American Association for Cancer Research, March 31-April 4, 2012, Chicago, IL, USA.

118. Peters S, Adjei AA. MET: a promising anticancer therapeutic target. Nat Rev Clin Oncol. 2012;9(6):314-326.

119. Bhardwaj V, Zhan Y, Cortez MA, et al. C-Met inhibitor MK-8003 radiosensitizes c-Met-expressing non-small-cell lung cancer cells with radiation-induced c-Met-expression. JThorac Oncol. 2012;7(8): 1211-1217.

120. De Bacco F, Luraghi P, Medico E, et al. Induction of MET by ionizing radiation and its role in radioresistance and invasive growth of cancer. J Natl Cancer Inst. 2011;103(8):645-661.

121. Qian LW, Mizumoto K, Inadome N, et al. Radiation stimulates HGF receptor/c-Met expression that leads to amplifying cellular response to HGF stimulation via upregulated receptor tyrosine phosphorylation and MAP kinase activity in pancreatic cancer cells. Int J Cancer. 2003;104(5):542-549.

122. Chu SH, Ma YB, Zhu ZA, et al. Radiation-enhanced hepatocyte growth factor secretion in malignant glioma cell lines. Surg Neurol. 2007;68(6):610-613.

123. Schweigerer L, Rave-Frank M, Schmidberger H, Hecht M. Sublethal irradiation promotes invasiveness of neuroblastoma cells. Biochem Biophys Res Commun. 2005;330(3):982-988.

124. Li B, Torossian A, Sun Y, Du R, Dicker AP, Lu B. MD higher levels of c-Met expression and phosphorylation identify cell lines with increased sensitivity to AMG-458, a novel selective c-Met inhibitor with radiosensitizing effects. Int J Radiat Oncol Biol Phys. 2012;84(4): e525-e531.

125. Aebersold DM, Kollar A, Beer KT, Laissue J, Greiner RH, Djonov V. Involvement of the hepatocyte growth factor/scatter factor receptor c-Met and of Bcl-xL in the resistance of oropharyngeal cancer to ionizing radiation. Int J Cancer. 2001;96(1):41-54.
126. Kim YJ, Go H, Wu HG, Jeon YK, Park SW, Lee SH Immunohistochemical study identifying prognostic biomolecular markers in nasopharyngeal carcinoma treated by radiotherapy. Head Neck. 2011;33(10):1458-1466.

127. Iveson T, Donehower RC, Davidenko I, et al. Safety and efficacy of epirubicin, cisplatin, and capecitabine (ECX) plus rilotumumab (R) as first line treatment for unresectable locally advanced (LA) or metastatic (M) gastric (G) or esophagogastric junction (EGJ) adenocarcinoma. Eur J Cancer. 2011;47:S443.

128. Smolen GA, Sordella R, Muir B, et al. Amplification of MET may identify a subset of cancers with extreme sensitivity to the selective tyrosine kinase inhibitor PHA-665752. Proc Natl Acad Sci U S A 2006;103(7):2316-2321.

129. Lutterbach B, Zeng Q, Davis LJ, et al. Lung cancer cell lines harboring MET gene amplification are dependent on Met for growth and survival. Cancer Res. 2007;67(5):2081-2088.

130. Nakagawa T, Tohyama O, Yamaquchi A, et al. E7050: a dual c-Met and VEGFR-2 tyrosine kinase inhibitor promotes tumor regression and prolongs survival in mouse xenograft models. Cancer Sci. 2010 101(1):210-215

131. You WK, McDonald DM. The hepatocyte growth factor/c-Met signaling pathway as a therapeutic target to inhibit angiogenesis. BMB Rep. 2008;41(12):833-839.

132. ClinicalTrials.gov. A study of onartuzumab (MetMAb) in combination with bevacizumab compared to bevacizumab alone or onartuzumab monotherapy in patients with recurrent glioblastoma. Available from: http://www.clinicaltrials.gov/ct2/results?term=NCT+01632228\&Sea rch=Search. Accessed May 16, 2013.
Lung Cancer: Targets and Therapy

\section{Publish your work in this journal}

Lung Cancer: Targets and Therapy is an international, peer-reviewed, open access journal focusing on lung cancer research, identification of therapeutic targets and the optimal use of preventative and integrated treatment interventions to achieve improved outcomes, enhanced survival and quality of life for the cancer patient. Specific topics cover in the journalinclude: Epidemiology, detc ection and screening Cellular research and biomarkers; Identification of biotargets and agents with novel

\section{Dovepress}

mechanisms of action; Optimal clinical use of existing anticancer agents, including combination therapies; Radiation and surgery; Palliative care; Patient adherence, quality of life, satisfaction; Health economic evaluations. The manuscript management system is completely online and includes a very quick and fair peer-review mont visit http://Ww system. Visit http://www.dovepress.com/testimonials.php to read real quotes from published authors. 